\title{
University Students' Perceptions toward an Online Interactive English Learning Platform
}

\author{
Dylan Sung*
}

\author{
Department of Applied Linguistics and Language Studies, Chung Yuan Christian University, Taiwan
}

\begin{abstract}
In recent times, the Ministry of Education in Taiwan has been urging universities to make the most of online learning. The purpose of this study was to investigate Taiwanese university students' perceptions and feedbacks regarding an online interactive English learning platform with a series of graded e-readers. The target population chosen for this study was the students at a selected university in northern Taiwan. A survey questionnaire was designed to collect data for this study. Results found that when the user interface is not intuitive and the experience is not smooth, students hold a fairly negative attitude towards the use of the online platform. Quality of the learning content can easily be overlooked if the users are not readily provided with easy navigation through the platform. The platform's lack of functionality for users to improve speaking skills is indicated as a major weakness. Furthermore, standardizing the use of an online English learning platform, as a mandatory part of an English course, can lead to adverse results. It is recommended that universities should thoroughly assess students' feedback and learning outcomes before computer technology is mandatorily incorporated into the syllabus of an English course.
\end{abstract}

Keywords: Language instruction, educational technology, instructional technology, online learning

\section{Introduction}

In December 2018, the National Development Council (2018) of Taiwan proposed new educational policies to develop Taiwan into a Chinese-English bilingual country by 2030. The expectation is that Taiwanese university students should be able to carry out communication in English outside of school and at the workplace after they graduate. Improving Taiwan citizens' English proficiency in the most widely used language in the global society is believed to enhance Taiwan's international competitiveness. The blueprint is intended to forge a culture of English learning for students to become equipped with strong international communication skills. Five guidelines were carefully formulated by the Ministry of Education (2018) to reach this important goal. One of the guidelines is to adopt a dynamic teaching approach with focus on daily English use to increase learning motivation. Another guideline is to utilize digital technology and promote individualized learning for young learners. These guidelines, along with recent changes in policy, call for instructional approaches that fit the different and shifting requirements.

It is clear that the newly announced English curriculum guidelines intend to encourage life-long learning and increase learner autonomy. The new guidelines aim to make the most effective use of digital learning outside the regular classroom. Similarly, more opportunities are said to be provided for students to learn and use the target language instead of sitting in the classroom and learning English from textbooks. Since the important proposal was first announced, the Ministry of Education (2018) has given several official responses to concerns regarding the decision on bilingual education in Taiwan. One of the responses indicated that the use of computer-assisted language learning (CALL) will indeed be greatly integrated. A comprehensive educational information platform that integrates various learning content will be set up for learning purposes. It will even feature a special section designated exclusively for English learning. Digital technology such as livestreaming, artificial intelligence, and even augmented reality have been mentioned to allow more accessible individualized learning (Wu \& Hsiao, 2018). 
The effectiveness of computer-assisted instruction in language learning has been the topic of a long-standing debate. Recently, Maryam, AliAsghar, Manoochehr, and Bahman (2018) performed a meta-analysis on the learning effect of computer-assisted English language instruction on a broad range of study features. The metaanalysis of the experimental literature compared computer-assisted English language learning with traditional face-to-face treatments. The results indicated that computer-assisted instruction had an overall medium effect on English language development. Moreover, the analyses indicated that web-based instruction yielded a larger mean effect than traditional computer-assisted instruction. In a recent cross-cultural study on the attitudes of English language students towards CALL, Tafazoli, Gómez Parra, and Huertas (2018) found that gender, age, and education level had no relationship to the attitudes of English language students towards CALL. The results showed positive attitudes of English language students towards computer-assisted learning. The study also concluded that English language students must be able to cope with technology-based educational materials in the near future.

In the EFL (English as a foreign language) context, the use of online learning has been effectively incorporated to considerable success. Online platforms could serve as a feasible alternative for teachers to assign learning tasks to students outside the classroom. They also grant teachers access to monitoring students' engagement with the task and enables them to evaluate achievements, particularly in the areas of students' learning to read, listen and write English (Mulyono, 2016). In writing courses, online discussion forums could be used to support learning of paraphrasing skills (Tan, 2017). Another major benefit of online platform is its ability to promote better interaction among students that are geographically distant from one another (Mohamad \& Shaharuddin, 2014). These advantages have been greatly recognized by the Ministry or Education in Taiwan as new content has been added and updated regularly to its free English learning platform made available for elementary school and junior high school students (Liao, 2018). Attention has especially been paid to add attractive functions deemed by the students.

As for the university level, Sung and Yeh (2012) conducted a qualitative study using interviews that explored Taiwanese university students' opinion on using language learning technology for foreign language learning. Results of the study showed that students generally held positive opinions on technology integration in foreign language learning due to its convenience and practicality. Students also pointed out that the flexibility to organize their own study plan as a positive trait of language learning technology. In another qualitative study that employed semi-structured interviews, Olejarczuk (2018) also found that learners of English for Specific Purposes showed generally positive attitudes towards the incorporation of CALL.

Fast Internet connections and the latest advancements in computer technologies provide many new ways for the innovations of educational technology. In reality, technology has become an indispensable part of higher education. Web-based technology has demonstrated its potential for use in a variety of learning activities to different learners (Aggarwal, 2003). Harper (2018) conducted a comprehensive review that examined studies published from 2005 to 2016 . Findings revealed that technology stimulates collaboration between teachers and students during learning activities. Additionally, technology also facilitates learning and promotes students' exploration of the content. Interactive textbooks, for instance, also motivate students to learn, make learning more exciting, and increase students' attention towards instruction in the class (O'Bannon, Skolits, \& Lubke, 2017).

Students, especially at the higher education level, regard the Internet as a fast and effective tool for learning purposes. A recent report by the Taiwan Network Information Center (2018) indicated that 94.1\% of Taiwanese people aged 15 to 19 and $98.5 \%$ aged 20 to 24 are Internet users. High availability, fast connections, and easy access make the Internet a real alternative to traditional classroom teachings. Moreover, the report showed that the highest percentages of content learned through platforms consist of learning languages which accounted for $44.8 \%$. The report also mentioned that the goal of Taiwan becoming a bilingual nation means that the use of 
digital technologies to build a bilingual nation will become a necessity. In addition to language education, the methodology and learning content can also be used to improve the usage rate of online learning.

The Ministry of Education in Taiwan has been actively promoting the use of digital technology on university campus (Ministry of Education, 2015). Many universities require faculty members to upload a certain percentage of course materials online. At a selected university in northern Taiwan, for example, online learning using an interactive learning platform takes up $10 \%$ of the final grade of any first-year general English course. The instructors may actually require other online activities in addition to this compulsory part of the course that involves the use of the particular learning platform. The Language Center at the selected university opted for an interactive learning platform with a series of graded e-readers developed by a well-known publishing company in the field of EFL learning. The e-readers are supported by post-reading online activities that reinforce learners' reading, listening, writing, and speaking skills. It has been discussed that the use of the e-readers may be required to a larger extent in the following academic year.

Considering the latest educational policies and requirements for online learning, it is crucial to find out students' viewpoints on this newly set requirement that may develop into a standard part in English courses. Specifically, the learning content should be carefully evaluated and revised according to the satisfaction level of the learners. Furthermore, learning features of the platform and students' perceived degree of importance, which has not been explored as much as level of satisfaction, should be explored as to identify areas that are in need of immediate improvement.

\section{Methodology}

The purpose of this study was to investigate Taiwanese university students' perceptions and feedbacks regarding an online interactive English learning platform with a series of graded e-readers. With the aim of achieving the stated purpose, the following objectives were established to guide the study:

1. To examine students' perceptions regarding English learning through an online interactive English learning platform; and

2. To determine learning features that require immediate improvement.

This study aimed to discover students' learning preference toward certain features and related functions associated with the interactive learning platform. Important areas that require immediate improvement were set to be identified as well.

Population and Sample

The target population of this study was the students at a selected university in northern Taiwan. Two classes, with 33 and 32 students respectively, taught by the researcher in the Fall 2018 and Spring 2019 semesters participated in the study. The great majority of the student were aged 18 to 19. All participating students had completed at least eight years of English learning since 5th grade. Based on standardized test scores obtained from the Language Center at the selected university, students in both classes possessed similar levels of English proficiency. Most of the students' TOEIC (Test of English for International Communication) scores ranged from 550 to 750 (limited working proficiency).

\section{The Online interactive English learning platform}

The Online interactive English learning platform was made by National Geographic's Footprint Reading Library. The selected university has full subscription to the platform. All students have free access to the learning content. The learning content of the platform is divided into eight different difficulty levels (grades). 
The assigned readings for the two classes were at the second highest difficulty level (advanced 2600 headwords). The choice was based on the fact that the two classes possessed the second highest proficiency level compared with the rest of the Freshman English classes in their respective college. Topics of the e-readers included animals, tourism, sports, health, environment, and etc. Functional features of the platform included video, fill in the blanks, e-reading, multiple choice questions, writing, discussion, grammar, matching, and supplementary reading.

All participating students used the online interactive English learning platform weekly for a month in the Fall 2018 semester and the Spring 2019 semester respectively. Students were asked to use all 10 functional features under investigation to become familiar with the various features.

To ensure students' thorough use of the various features, the following measures were employed. First, the Language Center kept a record of each student's activities on the learning platform. Second, the platform gave a score to every student for their performance on the various tasks. Third, the researcher administered a test based on the assigned learning content at the end of the learning period. Fourth, students' performance in the aforementioned areas would take up $10 \%$ of their final grade in the course.

\section{Instrumentation}

The researcher used quantitative methods to collect data in this study. A survey questionnaire was designed to collect data for this study. The survey contained 25 items and is divided into two parts: (1) the online interactive English learning platform and (2) importance level and satisfaction level of the learning features.

The items of the survey developed were in accordance with the actual learning content and features of the website. Part 1 of the questionnaire was designed with reference to previous studies. The first part aimed to investigate students' user experience as an English learner as well as their opinions on the effectiveness of the online platform as a learning tool. Part 1 of the instrument uses a five-point Likert-type scale which ranges from 1 (strongly disagree) to 5 (strongly agree). Part 2 of the questionnaire is structured in reference to the I-S Model. The second part aimed to identify learning features that need immediate improvement. This part also used a five-point scale ranging from 1 (very important) to 5 (very unimportant) for the degree of importance and 1 (very satisfied) to 5 (very unsatisfied) for the satisfaction level. Each item in this part required the participants to provide a pair of responses. The first in each pair deals with the degree of importance of the functional feature. The second deals with the satisfaction level of the functional feature. All items in both parts of the survey are presented in Table 1 and Figure 1 respectively in the Results section.

To assure the validity of the survey designed, all items of the instrument were evaluated. Two experienced CALL researchers, both with experience using the online interactive English learning platform under study, evaluated the ability of the instrument to investigate university students' perceptions and feedbacks. They also evaluated appropriateness of the survey in accordance with the concepts of CALL. Revisions were made based on the feedbacks provided. Expert validity of the instrument was obtained. The researcher, with a bilingual background, translated all the survey items into Chinese to assure better understanding by student participants and greater potential validity and reliability of results.

\section{Data Collection}

In March 2019, the researcher distributed the survey questionnaires to a total of 65 students from the two classes under study. The students who took part in the survey were informed that the questionnaire was not a test, and that their responses would be used for only research purposes. The instruction part of the survey pointed out that participation in the study is on a voluntary basis and students may withdraw during the process at anytime. The 
students were also assured that their responses would be adequately protected and no individuals were going to be identified.

The time needed to complete the questionnaires was less than 10 minutes. Appropriate ways to complete the questionnaire, especially part 2, were adequately explained by the researcher. The researcher also encouraged the students to carefully select their best response. All questionnaires were returned directly to the researcher to perform data analysis. Of the 65 sets of questionnaires returned, two of those had missing responses and were not included in data analysis. Out of the 63 respondents, there were 39 male students $(61.9 \%)$ and $24(38.1 \%)$ female students. All usable data from 63 (96.9\%) questionnaires were then entered and analyzed.

\section{Data Analysis}

For objective 1, descriptive analyses including means and standard deviations were performed. These methods examined students' perceptions regarding English learning through the online interactive English learning platform.

For objective 2, learning features were analyzed using the I-S Model. Functional features in need of immediate improvement were determined using the I-S Model. In the I-S Model, the horizontal dimension indicates the degree of importance of a particular functional feature, and the vertical dimension indicates the satisfaction level of the functional feature (Yang, 2003). The order pair (importance scale and satisfaction scale) can be located on the coordinates. The means of the importance scale and the satisfaction scale can be then used to divide the coordinate into four areas: excellent, to be improved, surplus, and care-free.

\section{Results}

The results of the survey are presented in this section. The researcher will firstly report the results of the students' perceptions on using the online interactive English learning platform. Next, students' perceived importance level and satisfaction level of the functional features will be reported.

\section{Online Interactive English Learning Platform}

Table 1 shows the descriptive statistics for the first part of the survey questionnaire. Overall, the participating students revealed a slightly negative perception on the platform $(M=2.95, S D=0.95)$. From the responses of the 63 participants, less than half of the questionnaire items, seven out of 15 to be exact, reached an average score of three or higher. Not a single item achieved a mean score of four or higher.

The highest rated item was that the speed of the audio tracks in the listening activities is appropriate $(\mathrm{M}=3.83$, $\mathrm{SD}=0.89)$. Out of the four basic skills, reading skills $(\mathrm{M}=3.78, \mathrm{SD}=0.76)$ were considered to be the most likely to improve by using the platform. That was actually the second highest rated item followed closely by the online interactive English learning platform can improve my English listening skills $(\mathrm{M}=3.62, \mathrm{SD}=0.90)$. In contrast, the lowest rated item was the online interactive English learning platform can improve my English speaking skills $(\mathrm{M}=2.06, \mathrm{SD}=0.88)$. It nearly achieved a mean score of lower than two.

The last four items on the questionnaire revolved around students' willingness and motivation to continue using the platform or similar websites for English learning inside and outside the classroom. The four items received a fairly low average score $(\mathrm{M}=2.49, \mathrm{SD}=0.90)$ across the board.

\section{Table 1: Online Interactive English Learning Platform}

\begin{tabular}{lcc}
\hline No. $\quad$ Item & M & SD \\
\hline 1. The interface of the online interactive English learning platform is simple to navigate. & 2.65 & 1.05 \\
\hline
\end{tabular}


2. The arrangement of the learning materials of the online interactive English learning $3.29 \quad 0.86$ platform is suitable.

\begin{tabular}{lcc}
\hline 3. It is stress-free to use the online interactive English learning platform to study English. & 3.17 & 0.98 \\
\hline 4. The speed of the audio tracks in the listening activities is appropriate. & 3.83 & 0.86 \\
\hline $\begin{array}{l}\text { 5. The learning content or the materials of the online interactive English learning platform } \\
\text { are practical. }\end{array}$ & 3.60 & 0.83 \\
\hline $\begin{array}{l}\text { 6. The test questions of the online interactive English learning platform are helpful in } \\
\text { English learning }\end{array}$ & 3.14 & 0.93 \\
\hline 7. The online interactive English learning platform can improve my English grammar. & 2.62 & 0.96 \\
\hline 8. The online interactive English learning platform can improve my English listening skills. & 3.62 & 0.90 \\
\hline $\begin{array}{l}\text { 9. The online interactive English learning platform can improve my English speaking skills. } \\
\text { 10. The online interactive English learning platform can improve my English reading skills. }\end{array}$ & 3.06 & 0.78 \\
\hline $\begin{array}{l}\text { 11. The online interactive English learning platform can improve my English writing skills. } \\
\text { 12. Overall, I like using the online interactive English learning platform to study English. }\end{array}$ & 2.58 & 0.76 \\
\hline $\begin{array}{l}\text { 13. I am willing to continue using the online interactive English learning platform to engage } \\
\text { in self-English learning }\end{array}$ & 2.46 & 1.98 \\
\hline $\begin{array}{l}\text { 14. English classes can continue using the online interactive English learning platform as } \\
\text { part of the course materials. }\end{array}$ & 2.48 & 1.06 \\
\hline $\begin{array}{l}\text { 15. The experience of using the online interactive English learning platform raises my } \\
\text { motivation to use other English learning web sites. }\end{array}$ & 2.51 & 1.02 \\
\hline AVG & 2.95 & 0.95 \\
\hline
\end{tabular}

\section{Importance Level and Satisfaction Level of the Interface Functions}

Results of categorization from using the I-S Model are illustrated in Figure 1. The mean degree of importance for the 10 interface functions was 2.59. The mean satisfaction level was 2.92. The mean degree of importance is used as the horizontal axis. Conversely, the mean satisfaction level is used as the vertical axis. The two axes divide the coordinate into four quadrants.

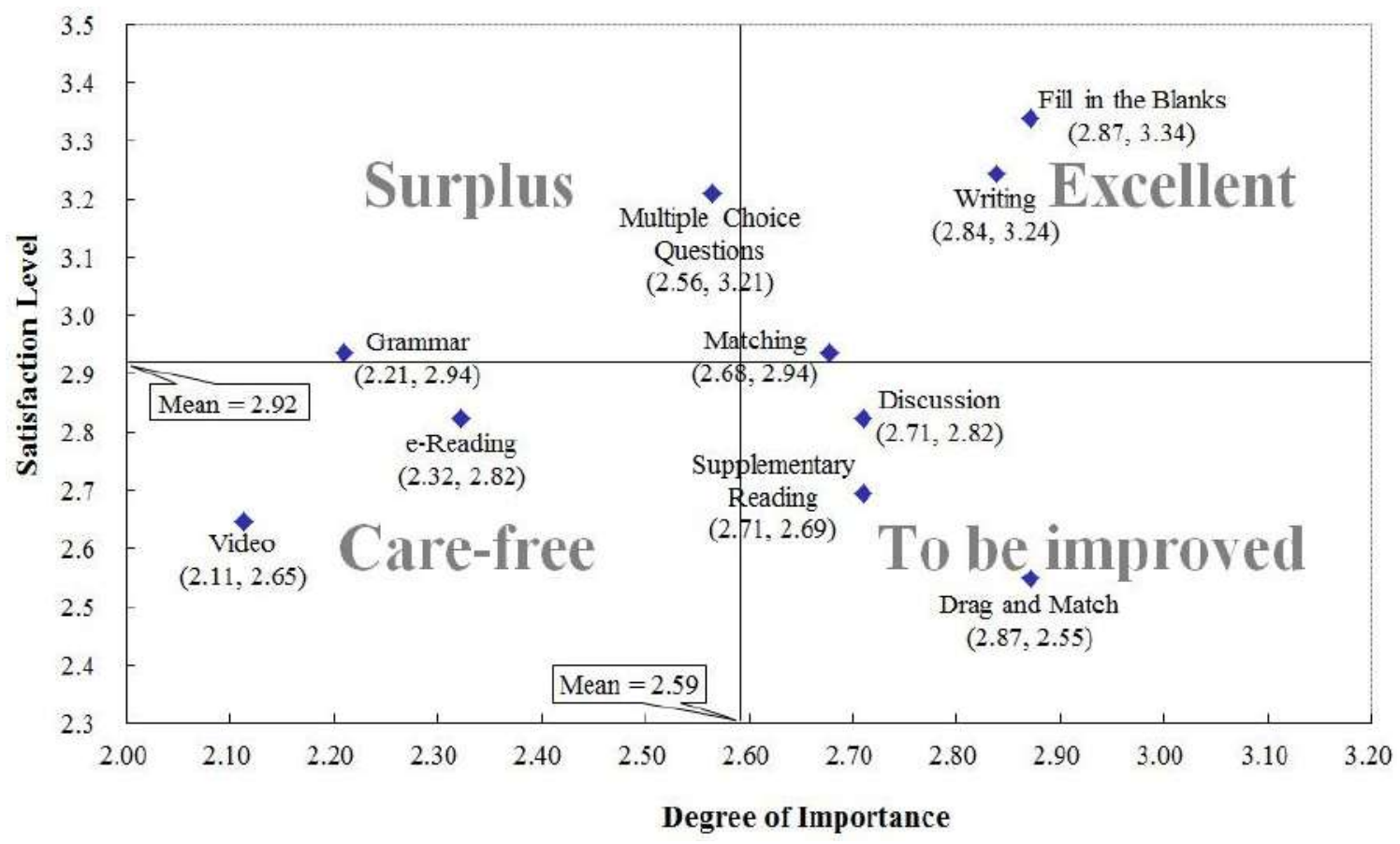




\section{Figure 1: Categorization of Functional Features in the I-S Model}

On the degree of importance scale, fill in the blanks as well as drag and match were found to be the most important $(M=2.87)$ functional features. The least important was video $(M=2.11)$. On the satisfaction level scale, fill in the blanks received the highest rating $(\mathrm{M}=2.87)$. Drag and match, the functional feature that was found to be the most important, received the lowest rating $(M=2.55)$ on the satisfaction level scale.

The results indicate that there are three functional features located in the to be improved area. Based on the ranking of importance, they are drag and match, supplementary reading, and discussion. Three functional features were categorized as excellent. Based on the ranking of satisfaction, they are fill in the blanks, writing, and matching. Multiple choice questions and grammar are in the surplus area. The remaining two functions, eReading and video, are in the care-free area.

\section{Discussion}

In spite of the obvious benefits, there is still an immediate need to improve the technology's design to functionally develop speaking skills (Sung \& Yeh, 2012). Results of the current study showed that regardless of the developers' claim of developing the technology with four skills in mind, the current technology is still limited in its capacity to engage students in useful speaking activities. On the other hand, the latest technology has improved upon a previous shortcoming, which prevented students from practicing writing exercises of any kind. However, the two output skills, namely speaking and writing, are still perceived as difficult to improve by using the online interactive English learning platform. This was not in line with previous studies that supported the notion that online learning platforms cold improve different writing skills (Mulyono, 2016; Tan, 2017). This limitation needs to be addressed by designers in order to achieve an optimal balance for students to acquire the four skills. In contrast, the platform's capability to improve the two input skills, namely listening and reading, were rated significantly higher than output skills. Efforts should be made to enhance the functional features of the technology to produce learning outcomes in the two output skills.

A very recent survey study that investigated students' attitudes, interests, and difficulties about CALL in a South Asian country revealed an interesting finding. The results found that male students had more positive attitudes towards CALL as compared to their female counterparts (Lodhi et al., 2019). It was also revealed that male students found CALL interesting for developing language proficiency while female students encountered more difficulties in using computer technology for English learning. In contrast, even though more than $60 \%$ of the participants of this present study were male students, they demonstrated a rather conflicting opinion. Crosscultural differences may exist in students' perceptions and user experience in the use of online technology in English learning.

Results of this study also bring a strong contrast to a similar study by Sung and Yeh (2012). That study, which dealt with a population similar to that in the present study, concluded that university students enjoyed the use of online technology for English learning. A possible explanation of the difference between the two studies was actually discovered after the formal investigation was over. Several students revealed that they did not utilize a computer to use the online interactive English learning platform. The sample of this study could possibly represent the Internet use habits of the current Taiwanese university students to some extent. In 2011, when the actual investigation of the aforementioned study by Sung and Yeh (2012) was performed, only $13.1 \%$ of the Taiwanese population were mobile Internet users. In 2018, the percentage was $76.9 \%$ (Taiwan Network Information Center, 2018). The overall design of the online interactive English learning platform under study was most suited to be used on a computer instead of a mobile phone. Of all 10 functional features, drag and match received the lowest rating of satisfaction possibly due to the activity being seemingly designed to be used on a computer monitor with a mouse instead of a mobile phone with considerably much smaller screen size. The navigation to perform many of the actions using a smartphone was reportedly very troublesome. The much 
smaller screen on a mobile phone could have made many of the learning activities that involved extensive reading difficult and exhausting.

In addition to being aware of language learning strategies for appropriate design of CALL to improve learning (Vincent \& Hah, 1996), designers of online English learning platforms will now need to take potential users' Internet use habits into consideration. The report by the Taiwan Network Information Center (2018) also stated that people in Taiwan use mobile phones as the predominant device to access the Internet. There is a clear shift in the way that people access the Internet and the devices that they use to do so. The technical limitations of mobile phones, especially in the area of navigation and screen size for reading, possibly prevented many students from achieving a positive user experience. As such, the learning content can easily be overshadowed by technical flaws of the technology. O'Bannon, Skolits, and Lubke (2017) also reported that students felt more cues were needed to alert less intuitive multimedia components in interactive textbooks to maximize learning outcome and user experience.

The above-mentioned finding regarding Internet use habits was discovered after the formal investigation. It was not included in the survey designed for this study. All data of this study were limited to quantitative responses. Subsequent studies should employ a qualitative design to collect further data regarding the online English learning platform. Aside from the technological aspects, interviews should also be conducted to elicit important information regarding students' viewpoints on the compulsory use of the platform in English courses. Similarly, a campus wide study should be conducted if the Language Center at the selected university considers the use of the platform a standard portion of English courses.

It is clear that students in this study showed negative attitudes towards the use of the online interactive English learning platform. This is quite different compared with studies that showed students generally exhibiting positive attitudes towards the incorporation of technology into foreign language learning (Lintou, 2015; Rahimi \& Yadollahi, 2012). When using computer technology is a mandatory part of an English course, students seem to have a higher preference for traditional classroom teachings instead. The interactive nature of the platform makes it more suitable for users' autonomous learning rather than being a required part of classroom instructions. However, the negative experience resulted in students' low willingness to continue using the platform even for self-learning, which was the main purpose behind the design of the technology. On the whole, students showed that they do not prefer the continuing use of the platform as a mandatory part of the English course.

The generalizability of this study is limited by the relatively small sample size. As such, findings of this study may not go beyond the selected university. Nevertheless, the Ministry of Education and universities in Taiwan should carefully assess the cost, effectiveness, learner preference, and learning outcome before the proposed large-scale platform that features a special English learning section is developed and implemented.

\section{Conclusions}

When the user interface is not intuitive and the experience is not smooth, students hold a fairly negative attitude toward the use of the online interactive English learning platform with a series of graded e-readers. Smartphones have come to the forefront that change the conventional Internet habits of Taiwanese university students. Quality of the learning content can easily be overlooked if the users are not readily provided with easy navigation through the platform. Furthermore, standardizing the use of an online English learning platform, as a mandatory portion of an English course, can lead to adverse results.

Despite generally negative perceptions, the platform is still considered relatively useful in improving input skills such as listening and reading. Still, the platform's lack of functionality for users to improve speaking skills is indicated as a major weakness. As all four skills are generally stressed in general English courses, this is one particular area that designers should really aim to make immediate improvements. English instructors, on the 
other hand, ought to place more emphasis on enhancing students' speaking skills to make up for the technology's current deficiency in this area. They should also be sufficiently familiar with the technology's strong points and shortcomings of all functional features of the platform. This would allow the instructors to take full advantage of the platform as a supplementary teaching tool on top of traditional classroom instructions.

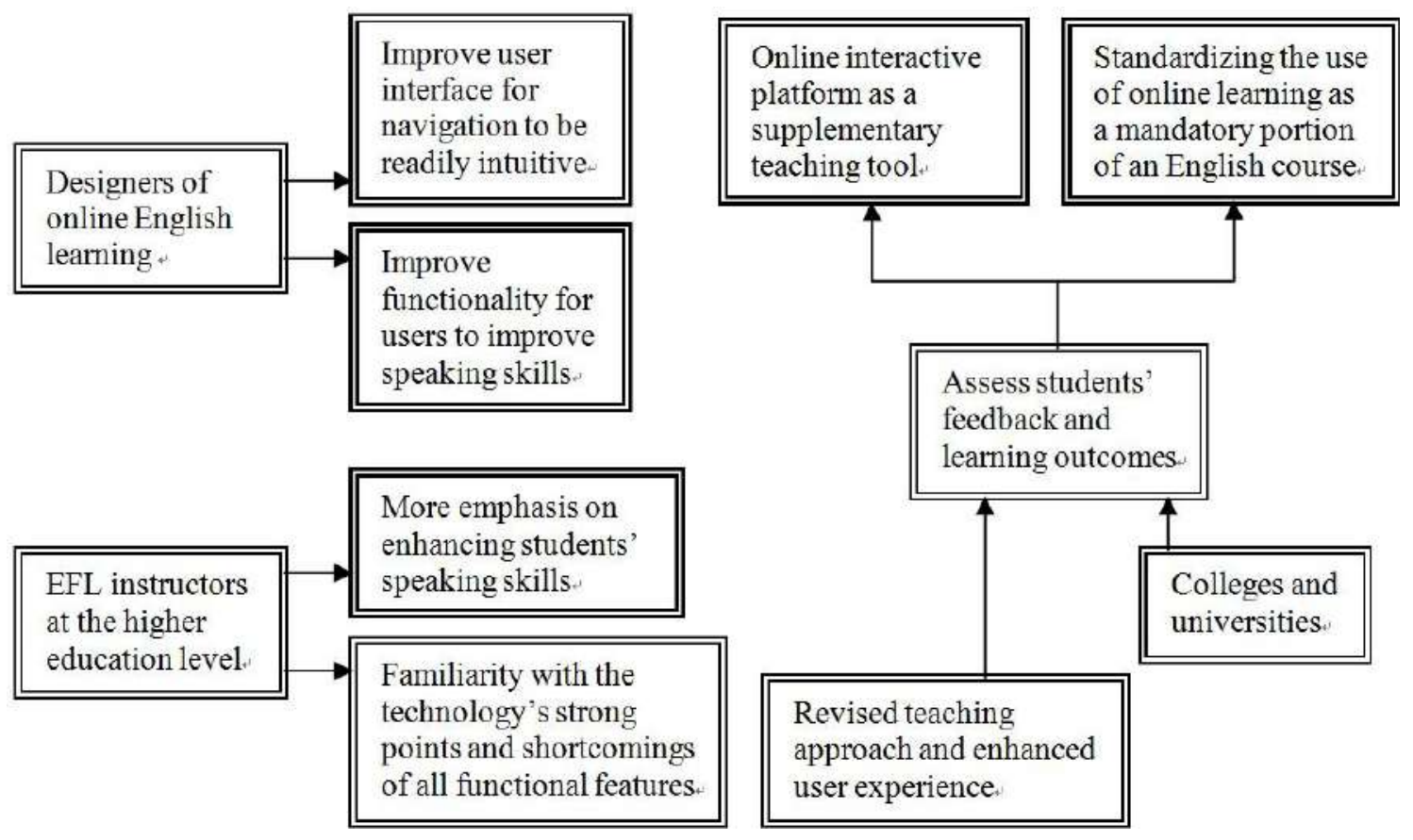

Figure 2: The Model of Utilizing Online Interactive Platform in an English Course

It is recommended that universities should thoroughly assess students' feedback and learning outcomes before computer technology is mandatorily incorporated into the syllabus of an English course. Figure 2 illustrates an integrated approach for universities to make important decisions on appropriately implementing the platform for effective English learning. Subsequent studies should employ an in-depth qualitative approach to discover how those weak areas can be improved based on students' Internet habits, user experience, and learning efficiency.

\section{References}

Aggarwal, A. (2003). Web-based learning and teaching technologies: Opportunities and challenges. Hershey, PA: Idea Group Publishing.

Harper, B. (2018). Technology and teacher-student interactions: A review of empirical research. Journal of Research on Technology in Education, 50(3), 214-225.

Liao, G. (2018). Taiwan's free online English learning platform 'Cool English' launches new functions. Taiwan News. Retrieved June 18, 2019, from https://www.taiwannews.com.tw/en/news/3419210

Liontou, T. (2015). Intermediate Greek EFL learners' attitudes to on-line teaching practices: A blended taskbased English language learning approach. Teaching English with Technology, 15(2), 81-93.

Lodhi, M. A., Fatima, A., Ismail, F., Amin, N., Khalid, F., \& Siddiqa, A. (2019). Attitude of male and female students towards computer assisted language learning at intermediate level. English Language Teaching, 12(3), $108-118$

Maryam, S., AliAsghar, R. A, , Manoochehr, J., \& Bahman, Z. (2018). Retrospect and prospect of computer assisted English language learning: A meta-analysis of the empirical literature. Computer Assisted Language Learning, 31(4), 413-436.

Ministry of Education (2018). Implement in full scale bilingualization of Taiwan's educational system; Cultivate bilingual talents to bring Taiwan to the world. Retrieved March 3, 2019, from https://english.moe.gov.tw/cp-13-17790-80201-1.html 
Ministry of Education (2015). Ministry of Education Objectives for 2016 (January-December). Retrieved June 18, 2019, from https://english.moe.gov.tw/cp-9-16462-0AC17-1.html

Mohamad M., \& Shaharuddin, S. (2014). Online forum discussion to promote sense of learning community among the group members. International Education Studies, 7(1), 61-74.

Mulyono, H. (2016). Using "Quipper" as an online platform for teaching and learning English as a foreign language. Teaching English with Technology, 16(1), 59-70.

National Development Council (2018). Blueprint for developing Taiwan into a bilingual nation by 2030. Taipei, Taiwan: National Development Council (Taiwan).

O'Bannon, B. W., Skolits, G. J., \& Lubke, J. K. (2017). The influence of digital interactive textbook instruction on student learning preferences, outcomes, and motivation. Journal of Research on Technology in Education 49(3-4), 103-116.

Olejarczuk, E. (2018). ESP learners' beliefs about CALL-A qualitative perspective. Language Learning in Higher Education, 8(1), 157-172.

Rahimi, M., \& Yadollahi, S. (2012). Multivariate effects of level of education, computer ownership, and computer use on female students' attitudes towards CALL. English Language Teaching, 5(4), 108-115.

Sung, D., \& Yeh, C. Y. (2012). Perceptions of using online technology in language education: An interview study with Taiwanese university students. Procedia - Social and Behavioral Sciences, 51, 405-410.

Vincent, E., \& Hah, M. (1996). Strategies employed by users of a Japanese computer assisted language learning (CALL) program. Australian Journal of Educational Technology, 12(1), 25-34.

Tafazoli, D., Gómez Parra, M. E., \& Huertas Abril, C. A. (2018). A cross-cultural study on the attitudes of English language students towards computer-assisted language learning. Teaching English with technology, 18(2), 34-68.

Taiwan Network Information Center (2018). Taiwan Internet Report. Retrieved March 19, 2019, from https://report.twnic.tw/2018/TWNIC_TaiwanInternetReport_2018_EN.pdf

Tan, K. E. (2017). Using online discussion forums to support learning of paraphrasing. British Journal of Educational Technology, 48(6), 1239-1249.

Wu, C. Y., \& Hsiao, S. (2018, December 5). Bilingual by 2030, council says. Taipei Times. Retrieved March 19, 2019, from http://www.taipeitimes.com/News/front/archives/2018/12/05/2003705515

Yang, C.C. (2003). Improvement actions based on the customers' satisfaction survey. Total Quality Management and Business Excellence, 14(8), 919-930. 